\title{
Tecnologias digitais de leitura e escrita: contributos para uma aprendizagem motivada
}

\author{
Estela Pinto Ribeiro Lamas*, Manuela Neto** \\ *Universidade Metodista Unida de Moçambique, **Escola Básica e Secundária de Ourém / Universidade de Santiago de Compostela
}

\begin{abstract}
Resumo
Vivemos numa época em que a consciência de que o mundo passa por transformações profundas é cada dia mais forte. Esta realidade provoca nas pessoas/alunos, sentimentos, sensações e desejos contraditórios e, ao mesmo tempo, insegurança, medo, conformismo mas, também, novidade e esperança. Sendo os alunos nativos digitais, o contexto escolar deverá ter em consideração a introdução das novas tecnologias nas práticas pedagógicas, pois elas fazem parte do dia-a-dia dos jovens. As tecnologias criam novas oportunidades de aprendizagem, desafiando as instituições educativas tradicionais. Há, por isso, uma necessidade de inovação pedagógica, aproveitando os dispositivos móveis para potenciar o gosto pela leitura/escrita e pela aprendizagem da língua materna.

Palavras chave: leitura; autobiografia; aprendizagem digital; TIC.
\end{abstract}

\section{O ensino da LM}

Ensinar a língua materna constitui-se um duplo desafio, para os professores, na medida em que temos de ter em conta o ensino e a aprendizagem da língua, enquanto objeto de estudo - dimensão científica - e enquanto instrumento de comunicação e veículo de informação - dimensão transversal - que se assume como fundamental para o desenvolvimento de saberes de outras áreas do conhecimento. Assim, impõe-se um ensino dinâmico e constantemente em atualização, pois é necessário ajudar os alunos a desenvolverem aptidões que os coloquem à altura dos desafios na nova sociedade do século XXI. É neste sentido que consideramos essencial o recurso às tecnologias de informação e comunicação [TIC].

As TIC possibilitam um maior acesso à informação, em tempos e espaços completamente distintos dos utilizados no ensino tradicional. A rapidez com que a informação circula e com que as pessoas comunicam entre si mudaram e a escola tem de acompanhar este novo dinamismo social. Há pois que trazê-las para a escola e pô-las ao serviço da educação, aproveitando pedagogicamente as suas potencialidades. Acreditamos que as próprias técnicas de expressão oral e, particularmente, escrita, estão em mudança em sequência da proliferação dos meios digitais.

Este é mais um factor que se acrescenta à importância do ensino e aprendizagem da língua materna. Espera-se que ela seja desenvolvida pelos alunos como uma ferramenta essencial para a descoberta de novos horizontes. É com a língua que conseguimos exprimir as nossas emoções e comunicar com o mundo. Ela é a maior forma de expressão comunicativa do ser humano.

\section{Problemática e investigação doutoral}

Como docente de Português, sempre tive a perceção de que a leitura/escrita são essenciais na formação escolar. Desde que nascemos, aprendemos a interpretar gestos, olhares, palavras e imagens. Esse processo é potencializado pela escola, por meio da leitura e da escrita, o que nos dá acesso a grande parte da cultura humana. A ideia de tratar a temática dos vários 'eus' nos textos autobiográficos resultou de uma convergência de fatores de natureza pessoal, académica e profissional, passados e presentes, bem como da atualidade e pertinência do tema em contexto escolar. A partir do momento em que surgiu, no Programa da disciplina de Português (2008), preconizado pelo Ministério da Educação, o Contrato de Leitura, parâmetro obrigatório na avaliação dos alunos, demo-nos conta que uma grande parte dos discentes não possuía hábitos frequentes de leitura.

Aprofundar a prática da leitura e da escrita dos nossos alunos representa um objetivo que pretendemos atingir, pois consideramos fundamental o desempenho dos professores na criação de uma comunidade de leitores/escritores eficientes e assíduos. A leitura e a escrita representam um diálogo entre o leitor e o texto. É dessa forma, papel do docente promover a interação entre ambos e tentar conduzir e orientar o aluno a ler nas entrelinhas, refletindo sobre o sentido global do texto, embora nunca perdendo de vista o prazer do ato de ler e escrever ressaltando a liberdade contida nesse ato.
A leitura, a escrita, o 'eu'
Aprofundar a prática da leitura e da escrita dos nossos alunos representa um objetivo que pretendemos atingir ao longo desta nossa caminhada, pois consideramos fundamental o desempenho dos professores na criação de uma comunidade de leitores/escritores eficientes e assíduos. A leitura e a escrita representam um diálogo entre o leitor e o texto. É, dessa forma, papel do docente promover a interação entre ambos e tentar conduzir e orientar o aluno a ler nas entrelinhas, refletindo sobre o sentido global do texto, embora nunca perdendo de vista o prazer do ato de ler e escrever ressaltando a liberdade contida nesse ato, a beleza da literatura. Em consequência, o aluno está sendo conduzido à perceção da leitura e da escrita como algo vivo e dinâmico. Como afirma Vítor Cruz (2007, p.123) “O domínio da leitura é a mais fundamental habilidade académica para todas as aprendizagens escolares, profissionais e sociais".
De modo a proporcionar aos alunos um leque diversificado de abordagens, promovemos várias 
atividades tais como o estudo literário de autores de reconhecido mérito; aprofundamos as componentes humanista, social e artística que definem a identidade cultural e ajudam na formação e desenvolvimento pessoais; desenvolvemos o ato reflexivo e o espírito crítico, através da leitura, o que leva a pensar no mundo e na sua posição no mundo, a encontrar-se a si mesmo e a sua posição na sociedade. Pretende-se transformar os alunos em leitores e escritores mais assíduos e competentes, quer ao longo do percurso escolar, quer durante a sua vida futura pois "A escrita deve ter significado para as crianças, despertando nelas uma necessidade intrínseca e deve ser incorporada numa tarefa necessária e relevante para a vida." (Vigotski, 1988, citado por Niza, 1998, p.58).

\section{Metodologia}

A metodologia usada neste trabalho doutoral, é a de investigação-ação. É uma metodologia que procura, não apenas recolher informação para descrever um problema, mas também propiciar o desenvolvimento de um ciclo de ações recorrentes para o solucionar. Isto é, pressupõe a articulação interativa e cíclica entre quatro atos: conhecer, planear, intervir e avaliar.

O estudo em causa é, pois, de natureza qualitativa. Entende-se por investigação qualitativa aquela que analisa os dados de forma interpretativa. As estratégias que esta utiliza permitem a descoberta de ligações entre fenómenos, provocando a emergência de novos pressupostos. Estes fenómenos são compreendidos pelo investigador através da perspetiva dos participantes, procurando os diferentes enfoques, com vista a um aprofundamento da questão.

A recolha de dados será efetuada com base na observação ou na investigação participativa, num ambiente natural, onde o investigador é o elemento principal desta atividade. A descrição e a análise de dados serão realizadas, através de uma exposição narrativa e tendo por base uma perspetiva indutiva.

No sentido de recolher informações aos níveis da leitura e escrita, bem como a respeito dos alunos selecionados, são utilizadas as técnicas de observação participada e naturalista. Esta última centra-se na observação do comportamento dos alunos, em sala de aula, realizada em meio natural na descrição e quantificação de comportamentos.

As evidências a recolher consistem de textos, testes, exercícios de escrita criativa e grelhas de registo, conducentes a uma auto e heteroavaliação; serão analisadas descritivamente, apresentando dados quantitativos e qualitativos, de forma a responder às questões de investigação, procurando verificar se é conseguida uma melhoria, bem como concluir se é possível melhorar a qualidade da resposta educativa e a prática pedagógica.

Considerando as técnicas de investigação-ação metodologia da qual este trabalho é apenas um experimento para um futuro aprofundamento pretendemos proceder a uma análise qualitativa dos dados obtidos e a uma reflexão sobre os mesmos, de forma a confrontá-los com o problema inicial, por nós apresentado. A avaliação qualitativa prende-se com a natureza da investigação-ação, que visa, essencialmente, valorizar a descoberta e compreender o desenvolvimento do processo.

Para questões relacionadas com o levantamento de interesses e expectativas dos alunos, recorremos também ao questionário por inquérito, fechado. Este permite-nos ainda traçar o perfil leitor dos nossos alunos. A escolha do questionário fechado prende-se com o facto deste instrumento ser mais objetivo, permitir ao inquirido selecionar a opção que mais se adequa à sua opinião, haver uma maior uniformidade na análise das respostas e uma maior facilidade na categorização das respostas para posterior análise. O questionário, segundo Gil (1999, p.128), pode ser definido "como a técnica de investigação composta por um número mais ou menos elevado de questões apresentadas por escrito às pessoas, tendo por objetivo o conhecimento de opiniões, crenças, sentimentos, interesses, expectativas, situações vivenciadas etc."

\section{Os alunos envolvidos}

O estudo que estamos a desenvolver, a nível do doutoramento, conta com um público-alvo num total de quarenta e quatro alunos; destes, dezanove são do sexo masculino e vinte e cinco são do sexo feminino. A média de idades varia entre os catorze e os dezasseis anos. Encontram-se a frequentar o $9^{\circ}$ e o $10^{\circ}$ anos de escolaridade. Quinze alunos são da turma A do $9^{\circ}$ ano, do $3^{\circ}$ ciclo do ensino básico, os restantes vinte e nove são da turma $\mathrm{B}$ do $10^{\circ}$ ano, do ensino secundário, do Curso Científico-Humanístico de Ciências e Tecnologias.

Ao longo do ano letivo, os alunos do $9 .^{\circ}$ ano mostraram-se motivados e empenhados em realizarem as atividades propostas. $\mathrm{O}$ final de ciclo e a realização do exame nacional, no final do ano, revelaram-se uma constante preocupação para estes discentes.

Relativamente à turma do $10 .^{\circ}$ ano, ao longo do ano letivo, os alunos revelaram-se pouco empenhados e com aproveitamento pouco satisfatório, manifestando alguma indefinição em relação à orientação vocacional realizada, comportamentos caraterísticos de alunos imaturos e em fase de adaptação à transição de ciclo. Vários alunos não estão na área de estudos pretendida e outros não têm ainda bem definida a sua orientação vocacional. De acordo com a análise de avaliação do $3 .^{\circ}$ Período, apenas dezassete discentes não apresentaram níveis negativos.

Contudo, estes alunos revelam-se de um modo geral, bem-dispostos e respeitadores, estabelecendo-se facilmente um clima de cumplicidade entre alunos e professora, facilitador do processo de ensino e aprendizagem.

\section{A dimensão cíclica que orienta o trabalho}

Acreditamos que uma boa planificação dá azo a um professor preparado, organizado e seguro, o que faz com que a aula seja, por sua vez, clara, rigorosa e dinâmica, evitando assim eventuais distúrbios.

Desta forma, no início do ano letivo, procedemos à macro planificação, em conjunto com as duas colegas que lecionam o $10^{\circ}$ ano. 
Através de um inquérito por questionário feito aos alunos das duas turmas $\left(9 .^{\circ} \mathrm{A}\right.$ e $\left.10 .^{\circ} \mathrm{B}\right)$ sobre os seus hábitos e gostos pela leitura vamo-nos gradualmente apercebendo de que, por um lado, a grande falta de hábitos de leitura é uma caraterística que abrange a quase totalidade dos alunos e de que, por outro lado, um número considerável não lê porque não gostava de ler, como os próprios gostavam de afirmar, considerando a leitura uma atividade monótona.

Podemos concluir, face aos resultados apresentados, que, sendo um dos nossos objetivos primeiros a leitura e a escrita, temos um trabalho acrescido, que passa pela motivação para o desenvolvimentos deste domínio da aprendizagem da língua materna,

Assim, planificamos as aulas, colaborámos com a BE e o grupo disciplinar de português, procurámos envolver-me o mais possível na vida da escola, motivando os alunos, sobretudo os do $9 .^{\circ}$ ano para o envolvimento de uma atividade nas Jornadas Culturais, intitulada "Tenda da Leitura", colaborando na consecução de materiais alusivos à leitura. Definimos objetivos e refletimos acerca da prática desenvolvida para avaliar os resultados alcançados e as melhorias produzidas em prol desse objetivo.

Ultrapassada esta planificação macro, procedemos a uma planificação de médio prazo, uma vez que sentimos a necessidade de adaptar a planificação de escola - a anual, macro - à realidade e ao contexto das nossas turmas e dos nossos alunos. Por fim, elaboramos a planificação de aula, sempre de acordo com os ritmos, interesses e necessidades dos nossos alunos.

Seguindo a articulação interativa, é fundamental conhecer bem os alunos para poder planificar segundo as realidades. Com mudanças inovadoras nos processos de trabalho, melhores teorias e técnicas, os discentes constroem novos conhecimentos, desenvolvem autonomia, sentem-se atores e autores nas suas aprendizagens. Existem, ao mesmo tempo, espaços de partilha de conhecimentos e experiências, desenvolve-se trabalho colaborativo. Enquanto docente, sentimos necessidade demudar algumas práticas pedagógicas para, efetivamente, obtermos sucesso educativo. Constatamos que é essencial implicar os alunos na construção dos seus saberes, respeitar as suas diferenças sociais, ir ao encontro das suas vivências e promover aprendizagens significativas.

Seguidamente, avaliamos as produções escritas dos alunos, ou seja, os relatos de experiências/vivências/memórias, fechando, assim, o ciclo. Perante os resultados obtidos e reformulações contínuas da produção escrita, encontramo-nos numa espiral de ciclos entre o conhecer, planear, intervir e avaliar, que se retoma em cada tarefa de forma contínua e sequencial.

$\mathbf{1}^{\mathrm{a}}$ sequência de aprendizagem. A nossa prática pedagógica na turma $10^{\circ} \mathrm{B}$ inicia-se no segundo período, com uma primeira unidade didática. Planificamos uma sequência didática que inclui seis aulas de noventa minutos cada, para lecionar os textos autobiográficos. Esta unidade tem como objetivos aprofundar a prática da escrita como meio de desenvolver a compreensão da leitura, promover o relato de vivências e experiências pessoais e promover a autorreflexão.

$\mathbf{2}^{\mathbf{a}}$ sequência de aprendizagem. A segunda sequência de aprendizagem tem como temática a abordagem a textos expressivos e criativos de poetas do séc. XX, traçando como objetivos a promoção do gosto pela leitura de poesia e o interesse na descoberta de poetas desse século; procura desenvolver estratégias de leitura para informação e estudo (pesquisa, organização de informação, etc.) e incentivar o espírito crítico e o trabalho de equipa.

\section{Reflexão e projeção}

Acabada a primeira etapa deste trabalho, podemos afirmar que ele decorreu de acordo com o planeado e conseguimos o envolvimento dos nossos discentes, o que cremos ser a primeira conquista e vitória, na medida em que, entendemos que o sucesso profissional de um professor passa primeiramente pela sua capacidade de motivar para a aprendizagem. Assumimos que não foi uma tarefa fácil à partida, pois notámos um grande receio na exposição oral, por parte de alguns alunos, na medida em que se tratava de uma tarefa com a qual não estavam familiarizados. A nível da leitura, houve também alguma resistência dos estudantes, pois, para além de não possuírem hábitos de leitura autónoma enraizados, a tipologia textual - texto lírico - pela carga simbólica e subjetiva que apresenta, não é apetecível aos jovens desta faixa etária. No que diz respeito à escrita, destacamos duas reações distintas que traduzem a relação de familiaridade que os diferentes alunos têm com este domínio da língua portuguesa: por um lado, os alunos habituados a publicar as suas fanfictions, aderiram entusiasticamente às atividades de escrita; os que não praticam esta modalidade de escrita não manifestam interesse, face a tarefas relacionadas com este domínio. Contudo, quando consciencializados com o facto de que o seu ato de escrita se prendia com a temática da autobiografia, sentiram mais motivação e entusiasmo, para cumprirem as solicitações e propostas que apresentámos. Ultrapassada estas primeiras barreiras, sentimos que o envolvimento dos alunos foi aumentando, à medida em que íamos avançando na nossa prática e na sequência de aprendizagem planificada.

A terceira sequência de aprendizagem, a realizar entre setembro e dezembro de 2015, estará centrada na competência da oralidade. Os alunos serão avaliados pelo desempenho de apresentações orais, entre outras, baseadas no desenvolvimento de temas de obras dos conteúdos programáticos do $11^{\circ}$ ano de escolaridade, do ensino regular.

\section{Instrumentos de apoio à investigação}

Dos materiais utilizados consta um inquérito, grelhas de observação, a criação de dois blogs de turma (i) do $9^{\circ}$ A - fimdelinha9Ablogspot.com e (ii) do $10^{\circ} \mathrm{B}$ - leitura \& escrita10b.blogspot.com assim como um contrato de leitura.

Durante as aulas foram utilizados, para além do manual adotado, vários instrumentos de avaliação, tais como, entrevistas, grelhas de observação direta de 
participação, fichas de auto e heteroavaliação, testes de avaliação de conhecimentos.

O contrato de leitura. O programa de português para o Ensino Secundário em vigor aponta para o envolvimento do aluno/leitor no ato de ler, uma vez que aí se refere que a compreensão de um texto pressupõe que "o leitor integra (...) informação básica nos esquemas conceptuais que já detém, elaborando, em seguida, a sua representação individual, já enformada pelos seus conhecimentos /vivências."

Este contrato de leitura desenvolveu-se ao longo do ano letivo, com os alunos das duas turmas. A concretização desta atividade passou por várias etapas. A primeira consistiu numa conversa com os discentes, sobre os livros que andavam a ler e os que gostariam de ler, os temas de que mais gostavam, assim como o género de leituras preferidas. Na sequência desta conversa, eles foram informados da atividade a desenvolver bem como dos objetivos e avaliação que lhe estavam implícitos.

Esta iniciativa permitiu proporcionar aos discentes a descoberta de um grande número de livros, facultando a cada adolescente a possibilidade de ter "um encontro decisivo" com um deles, tentando, dessa forma, uma reconciliação com a leitura.

Empenhámo-nos em estimular o gosto pela leitura literária, percecionando o "Contrato de leitura" como mais uma iniciativa para informar os discentes sobre obras e autores, portugueses e estrangeiros, com mérito reconhecido. O importante, para estes alunos específicos, que dizem não ler, é oferecer-lhes oportunidades de leitura e fazer com que percebam que existe uma imensidão de livros sobre variadíssimos assuntos, até mesmo sobre aqueles que lhes interessam mais. Tentámos, através da leitura literária, levá-los a encarar o contrato, não como uma obrigatoriedade, mas como uma forma de descoberta do prazer de ler.

O inquérito - propósitos e contribuições. Com este estudo, tivemos a intenção de conhecer o perfil leitor dos nossos alunos, para melhor podermos contribuir para o estímulo do gosto pela leitura literária e para o desenvolvimento de hábitos de leitura, considerados fundamentais para a plena integração do indivíduo na nossa sociedade da informação, onde as competências de compreensão são, cada vez mais, postas à prova. Sabendo-se que uma grande parte dos jovens em idade escolar não tem hábitos de leitura diários e que a formação de leitores é missão da escola, é preciso refletir sobre esta realidade. É indubitavelmente necessário interrogarmo-nos sobre o significado que se atribui ao ato de ler no século XXI, sobre os discursos que devem estar presentes na aula de língua materna, sobre os contributos que a literatura pode trazer a essa mesma aula, enfim, sobre a forma como se ensina a ler/compreender. Tendo identificado um problema - na globalidade, os alunos não leem - procurámos compreender a sua real dimensão e natureza específica. Para isso, fizemos uma recolha de dados, através de um inquérito por questionário. Depois de termos analisado as respostas obtidas, foi possível traçarmos um percurso, delineando os objetivos específicos a atingir, de acordo com as reais necessidades dos adolescentes. Por conseguinte, dinamizámos diversas atividades, cuidadosamente pensadas e planificadas. Mediante as dificuldades detetadas, fomos investigando e apresentando alternativas, sem nunca esquecer os objetivos antes pensados. No final desta primeira etapa e, principalmente através do contrato de leitura e de alguns documentos produzidos pelos alunos, aferimos que as escolhas efetuadas foram adequadas, pois houve uma evolução positiva nos hábitos de leitura diários, assim como no gosto pela leitura literária. Todavia, ainda não chegamos ao fim do caminho. É preciso continuar este trabalho a favor da promoção do gosto pela leitura de textos literários, já que eles representam a simbiose perfeita que torna possível ter prazer na leitura e, simultaneamente, atingir os mais complexos níveis de literacia. Aplicando este método de investigação-ação ao ensino, pretendemos mostrar que é possível, e recomendável, aprender fazendo, e que a reflexão sobre questões essenciais, como as capacidades e o papel de cada interveniente, o objeto de estudo e a aplicabilidade prática de algumas teorias, conduz sempre a uma melhor adequação do desempenho de cada um.

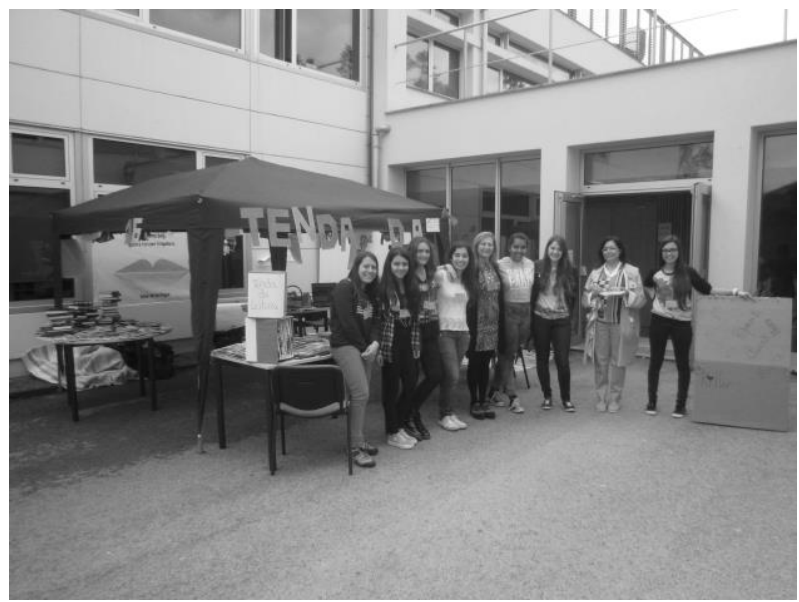

Figura 1 - Tenda da Leitura, Jornadas Culturais, Escola Secundária de Ourém

\section{O potenciar da aprendizagem}

A sala de aula não é o único espaço onde o aluno pode aprender. Fora das quatro paredes da sala de aula, a aprendizagem torna-se mais enriquecedora. $\mathrm{O}$ mais importante, no fundo, é que os alunos consigam desenvolver a autoconfiança, o espírito crítico e a livre iniciativa. Através da atividade "Tenda da Leitura" os alunos puderam por em prática os seus conhecimentos, quando leram aos colegas mais novos diversas histórias, partilharam os seus saberes, desenvolveram um conjunto de atitudes e capacidades tais como saber aprender, pesquisar, selecionar informação, concluir e comunicar. 


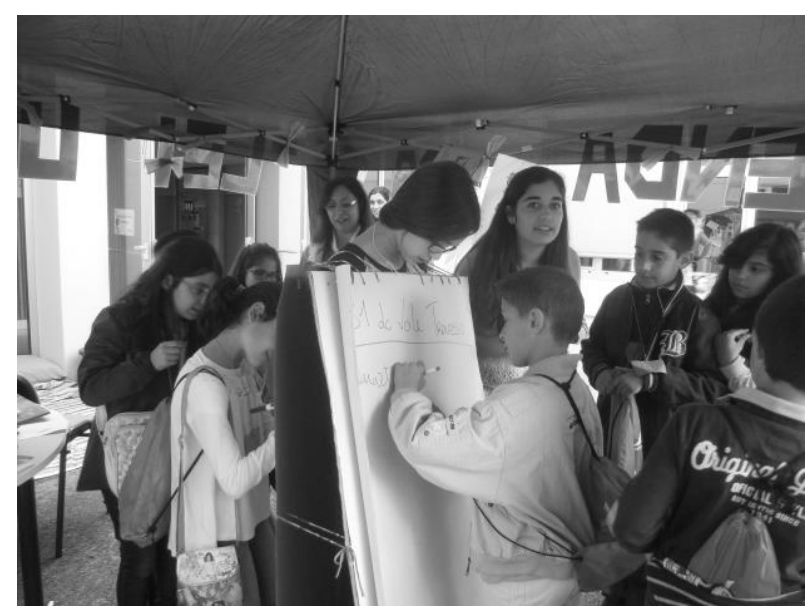

Figura 3 - Participação dos alunos do $1^{\circ}$ Ciclo na atividade

\section{Por uma prática pedagógica inovadora}

Num mundo em que a evolução tecnológica marca o quotidiano das sociedades e o acesso às tecnologias está cada vez mais facilitado, consideramos a necessidade de desenvolvimento de competências gerais como a escrita, e a leitura, associadas ao desenvolvimento dessas mesmas capacidades nos alunos, fomentando as suas capacidades criativas.

Refletimos sobre a forma como se pode ensinar e aprender na aula de Português com recurso às tecnologias é, a nosso ver, o aluno, que é o centro do processo de ensino e aprendizagem manifesta, com grande entusiasmo, as suas vivencias, destacando aspetos que de outra forma teria mais dificuldade em partilhar. Com a vantagem de ligar os processos de aprendizagem aos conteúdos através das tecnologias, cativámos os alunos a publicar as suas fanfictions, as suas memórias, os seus diários e à criação dos seus próprios blogs.

Os dispositivos móveis - sua funcionalidade. $O$ programa de português para o Ensino Secundário atualmente em vigor considera que uma das finalidades da disciplina é "proporcionar o desenvolvimento de capacidades ao nível da pesquisa, organização, tratamento e gestão de informação, nomeadamente através do recurso às novas Tecnologias de Informação e Comunicação" o que pressupõe a existência de recursos adequados ao desenvolvimento do saber, mas também do saber-fazer. A utilização do Tablet, do Moodle, do Blog de turma permitiram que o processo de ensino e aprendizagem fosse concebido de forma a permitir uma perfeita integração entre as ferramentas tecnológicas e as ações de aprendizagem utilizadas na sala de aula e, dessa forma, difundir conhecimento.

\section{Reflexão e projeção}

Para que os nossos alunos tenham sucesso escolar e sejam, a posteriori, profissionais competentes e cidadãos completos, importa que cada professor seja também um bom leitor e um investigador incansável para poder transmitir o gosto pela leitura e conceber práticas pedagógicas motivadoras e criativas dentro e fora da sala de aulas. Entendemos que cabe ao professor de português (embora não exclusivamente) o importante papel de revitalizar a leitura, selecionando os textos adequados (sempre que isso seja possível), propondo atividades motivadoras, recorrendo a estratégias criativas e servindo-se dos vários meios/suportes existentes, de forma a desenvolver as competências literácitas dos discentes, levando-os à fruição dos textos.

\section{Considerações conclusivas}

Consciente do papel preponderante que o desenvolvimento das competências leitoras assume nos dias de hoje, pautámos a nossa atividade letiva ao longo deste ano pela apresentação aos alunos de diferentes tipos de textos literários, em suportes variados, adequando e diversificando as estratégias e as modalidades de leitura às várias finalidades visadas: ler para construção da significação dos textos, visando uma análise crítica - leitura analítica e crítica; ler para construção de conhecimento - leitura funcional; ler para fruição estética e pessoal dos textos - leitura recreativa. Com as atividades propostas tentámos "fazer do aluno um leitor ativo, capaz de selecionar informação, formular hipóteses, construir sentidos, mobilizando referências culturais diversas, comparar/confrontar textos lidos, tornando-se progressivamente mais competente como leitor.

Tal como a mãe que educa o seu filho, repetindo incessantemente as mesmas palavras, os mesmos gestos de afeto, o professor-educador deve ser resiliente e acreditar que as sementes que lança, e que frutificarão um dia, são fundamentais para a construção da identidade de cada indivíduo, para a sua formação para o desenvolvimento da sua sensibilidade e da sua criatividade.

\section{Referências}

Rocha, M.S.S. (2012). Ensino da Língua Materna: Pensar, Comunicar e Interagir. Documento eletrónico retirado de http://www.jornalcorreiodasemana.com/ css/index.php/literatura-cearense/133-ensino-da-lingu a-materna-pensar-comunicar-e-interagir. Acedido em 1 de julho de 2015.

Coelho, M. C. (coord.) (2001/ 2002). Programa de Português 10. , $11 .^{\circ}$ e 12. ${ }^{\circ}$ anos. Cursos Cientifico-Humanísticos e Cursos Tecnológicos. Lisboa: Min-edu/DES.

Cruz, V. (2007). Uma abordagem cognitiva da leitura. Lousã: LIDEL - Edições Técnicas.

Gil, A.C. (1999). Métodos e técnicas de pesquisa social. 5. ed. São Paulo: Atlas.

Niza, S. (coord.). (1998). Criar o gosto pela escrita Formação de Professores. Lisboa: Ministério da Educação. 